\title{
Design of Field Standardization Management System for Electric Power Operation Based on B/S
}

\author{
Zhengwei Chang, $^{1,}$, Wei Zhang, b, ${ }^{2}$, and Xinzhong Xiong ${ }^{2, c}$ \\ ${ }^{1}$ State Grid Sichuan Electric Power Company Electric Power Research Institute, Chengdu, 610000, \\ China \\ ${ }^{2}$ School of Automation \& Information Engineering, Sichuan University of Science \& Engineering, Zigong, \\ 643000, China

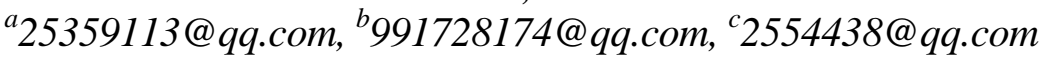

Keywords: Browser/Server (B/S) mode, project management system, production, management, system management.

Abstract: In order to achieve the standardized, reliable and efficient management of electric power operation, a system of field standardization management of electric power operation based on B/S mode is designed in this paper. This system has three main functions, including project management system formulation, production management and system management. With the help of B/S model, the designed system can play a significant role in numerous categories of large-scale projects, medium-sized projects and decentralized operations in the State Grid for different purposes, such as capital construction commission, technical supervision, technical services and so on. In addition, this conceived system can accomplish a safer field operation and a more concise operation management compared with the existing relevant systems. The operation of the State Grid reaches the expected level, and the effective management mechanism is corroborated in practical application.

\section{Introduction}

With the development of the economy and the acceleration of the reform of the power companies, people are constantly making new demands on the power companies. The power system is a large and complex system. Every part and equipment contained in the power system has a great influence on the operation of the whole power grid, whether the power quality is fit or not, so grid security and the power quality cannot be ignored. Therefore, the orderly, reliable and efficient on-site management is particularly important [1]. With the rapid development of Internet technology, the Client/Server (C/S) mode in the power plant equipment management system is being challenged by the emerging technology Browser/Server (B/S) mode. There are a lot of information in the equipment management system of power plant, and there are many items in the project. The traditional C/S mode has been used for a long time. Not only does it require the installation of client software, but it also makes the upgrade and maintenance of the system inconvenient, and there is no overall plan for the use of various departments. There are various kinds of management software, hence, it is difficult for departments to communicate with each other, and the automation level of work efficiency and management improve difficultly. To address this situation, B/S mode-based device management systems are increasingly 
used [2], [3].

The globalization of information has brought a qualitative leap to network technology, which also provides a very good platform for close exchanges and development on various technologies involved in the national grid. Therefore, in order to realize the field management of electric power operation, it is necessary to organize and manage various tasks through modern information technology. The globalization of information can greatly improve the reliability and efficiency of power operation management, reduce labor intensity and make full use of existing equipment, at the same time, it also save resources and strengthen the coordination of various departments of the company. The ability and management mechanism to ensure the smooth operation of electric power and bring considerable benefits to users and power companies.

The rest of this paper is organized as follows. Section II introduce the advantages of the B/S mode application and system construction. In section III, we present the design of electric power operation site standard management system. Finally, conclusions are given in section IV.

\section{B/S Mode Application and System Construction}

The $\mathrm{B} / \mathrm{S}$ mode is a new Web structure mode developed from the traditional two level $\mathrm{C} / \mathrm{S}$ mode, which is the improvement of $\mathrm{C} / \mathrm{S}$ mode. It distributes the presentation layer, the application layer and the data resource layer to different units: the presentation layer is composed of the browser and the dynamic Web page, receives and processes the users request, and passes them to the Web application server; in the Web structure, the transaction layer and the data logic layer are placed in the middle component layer, which is the key difference from the C/S structure [4]. The middle component layer acts as a server, that is, the Web application server, the application layer corresponds to the Web application server. The business logic processing process uses data resource layer services to obtain necessary information or store and modify corresponding data; the data resource layer corresponds to a database server. The database server implements database management and database access and various data operations. The $\mathrm{B} / \mathrm{S}$ mode simplifies the client without installing different client applications on different clients like the $\mathrm{C} / \mathrm{S}$ mode, but only requires safe and universal browser software. The B/S mode structure is shown in Figure 1[5].

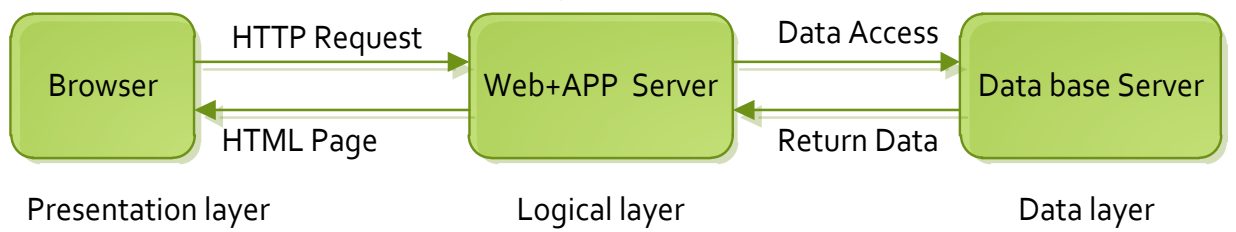

Fig.1 The B/S mode structure

The $\mathrm{B} / \mathrm{S}$ pattern has the following advantages [6]:

- It is convenient to maintain and upgrade, and only the development and maintenance of server-side applications are required without the development of client software;

- There is no requirement for the operating system and software platform, good openness and scalability;

- Support for multiple database access, there is no limit to the number of front-end users;

- The firewall technology can be used to ensure system security, and effectively meet the user's security needs of the system;

- The rapid update of information fully reflects the timely, rapid, flexible, and characteristics of the network information;

- It realizes the resource, systematization and standardization of information, and provides the possibility for further information mining and sorting. 


\section{Operation Process and Field Operation Management}

\subsection{Operation Process Management}

Power field operations in the national grid are an extremely cumbersome and extremely complex task, involving all levels of business processing and related management departments throughout the work process. In order to successfully complete all the work, we need to cooperate and communicate with them. Through reasonable planning and arrangement, we will connect them into a well-ordered whole. All the staff help each other and strictly follow the rules to implement the business process. This is the daily operation of the power agency. Improvement of quality and management efficiency, as well as improving the overall economic and social benefits of the company are very important [7].

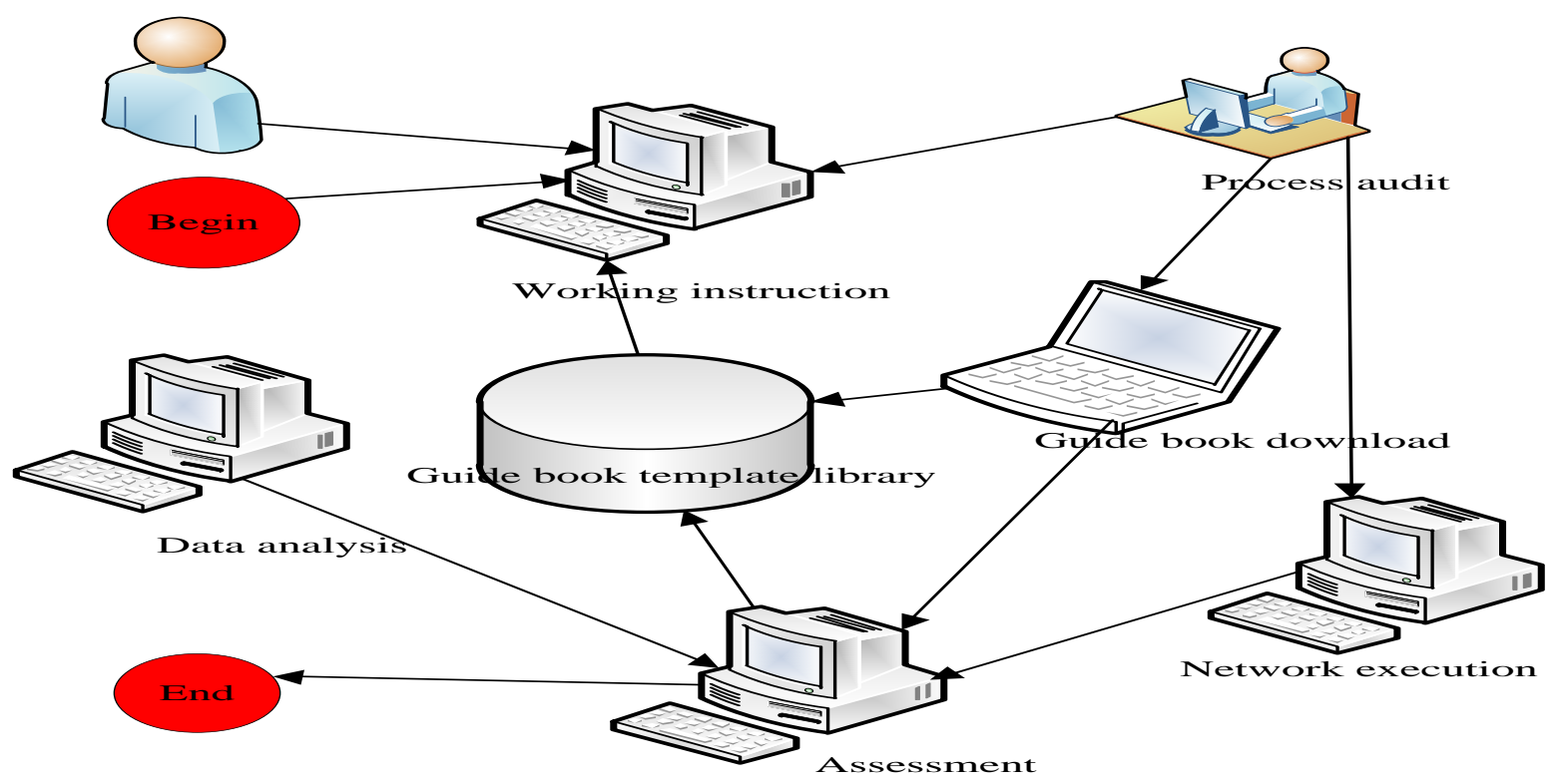

Fig.2 Basic process of job management

Through the analysis of the operation management process, we get the basic process of standard operation management of Sichuan State Grid Electric Power Academy. The system needs to be able to manage all power operations, including plan management, plan assessment, and task alarm processing. As shown in Figure 2.

\subsection{Field Operation Management}

The system adopts the multi-layer structure design concept and combines the security and convenience through the B/S model. Systems based on three-tier architecture are easier to implement, maintain, upgrade, and deploy, and they are also more reliable in operation. The module structure of the system is shown in Figure 3. 


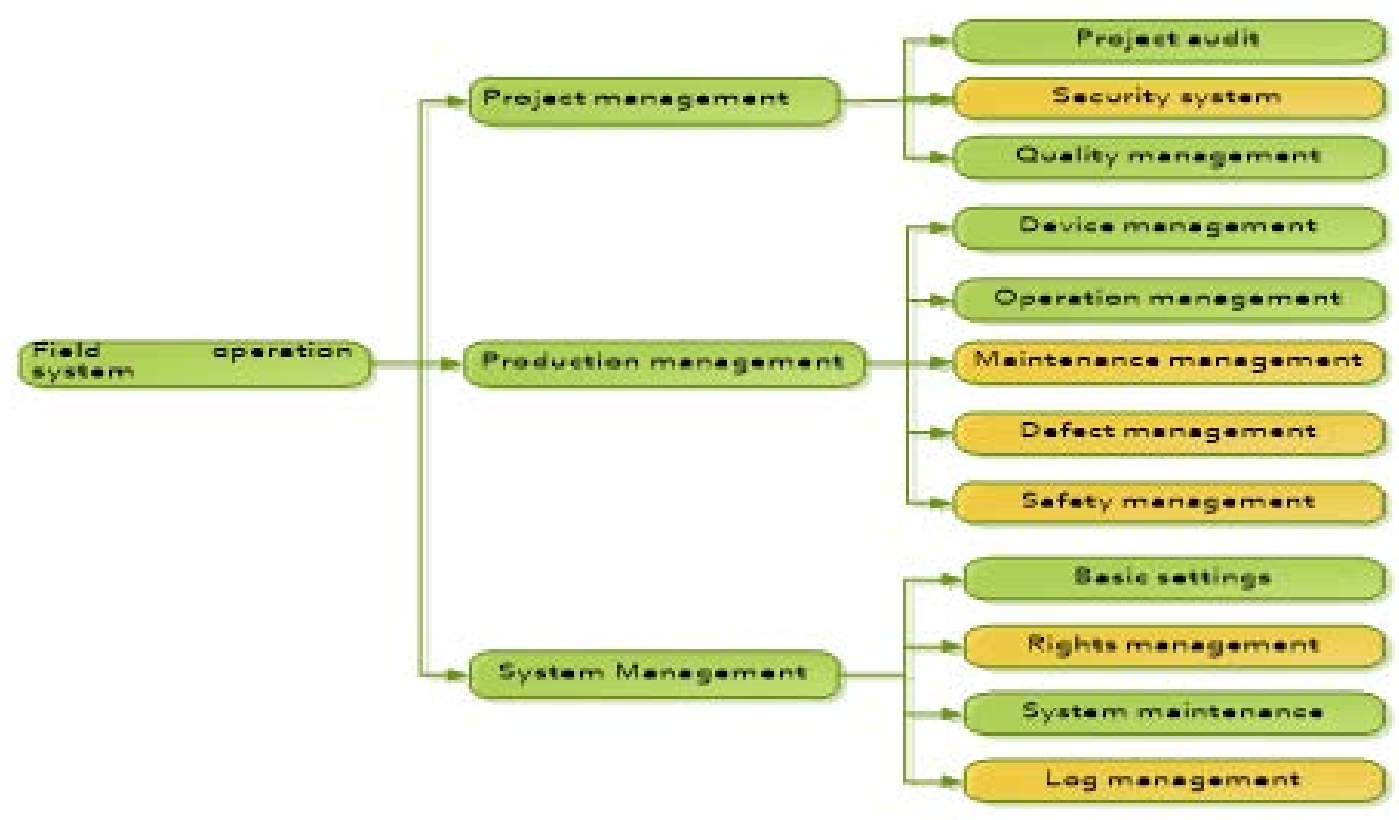

Fig.3 System structure module diagram

\subsubsection{Project Management System}

In the operation of the electric power company, some serious accidents often occur. In the final analysis, the equipment that is often mentioned is not fixed regularly, and the management is not strict. For such a long-standing problem, we must use the standardized system of field operations as soon as possible to reduce the occurrence of similar incidents. With the rapid development of information globalization, it is necessary to rely on a perfect power operation management system to truly realize the stable and reliable development of the power industry [8].

\subsubsection{Project audit}

The module is composed of two parts: the electric field operation project preparation system and the project summary filing system. The project preparation system includes the collection of related materials, plans for preparation work, the establishment of safety management and emergency response systems, and the preparation of materials and personnel and logistical support. A clear method of operation is formulated for the above-mentioned aspects; the project summary filing system is the project information and archiving time that need to be archived give accurate requirements and ensure that the entire project is completed on time according to quality and quantity. This module can make the whole project process can be rationally performed according to the work plan, and sort and organize the data to facilitate the maintenance and operation of the substation in the future power operation [9].

\subsubsection{Security system}

The module is composed of the safety responsibility system, education and training system, inspection and supervision system, regular meeting system, equipment and equipment and safety management system for transportation vehicles.

- The safety responsibility system is to implement the safety responsibilities of the project manager, project deputy manager, project department safety officer, work group; leader, work group safety 
officer, work group personnel, and expert advisor group members, so that each staff member understands himself the content of the work, so that the work can be carried out in an orderly manner [10];

- The education and training system requires the project leader to use the pre-class meeting, safety inspections, safety activities and other occasions to conduct flexible and diverse training for all project personnel, including pre-entry safety education, on-site safety education, and safety summary after the project ends. The problem of grid construction safety is to prevent the occurrence of safety accidents;

- Inspection supervision is to pay close attention to the on-site operation personnel's activity status, supervise and urge all staff members to strictly implement safe work procedures, stop unsafe behavior of operators, and put forward rectification requirements to eliminate hidden accidents in time;

- The regular meeting system requires that each professional field person in charge report the safety production situation of the professional, sum up this week's safety production work and existing problems. The person in charge of the project will deploy next week's key safety work, safety risk early warning, and prevention and control measures;

\subsubsection{Quality management}

The module is to realize the management of construction personnel qualifications, instruments and equipment, special machinery, project implementation plan, test plan, etc., from the roots of the strict quality control, the project implementation process must be strictly in accordance with the drawings, programs, work instructions Work, project quality must ensure that all technical parameters can meet the requirements, materials can be qualified, fully implement the standardization of operational requirements, is strictly prohibited fraud, to eliminate "bean curd residue" project to avoid major safety incidents in the future.

\subsubsection{Production Management}

\subsubsection{Device management}

This module mainly records and maintains all devices in the system, such as the model number and detailed parameters of all devices [11]. Through efficient and reasonable management mechanisms, the optimal planning layout is used to improve the utilization efficiency of the power equipment through the system path as far as possible. To maintain a good equipment state of the power system, provide and develop a scientific and reasonable maintenance strategy, and the management of the standby recovery system is the main content of the equipment to ensure the safety and stability of the power grid system.

\subsubsection{Operation management}

This module is mainly responsible for the normal operation, safe production and complete power dispatching tasks of high-voltage and weak-current equipment and buildings of the State Grid Power Company. According to the analysis of the operating status of the equipment, the performance status of the equipment is tracked, and the trend of the status change is monitored to ensure the normal operation of all the equipment. 


\subsubsection{Maintenance management}

The main functions of the module include the comprehensive management of the information and maintenance information of the maintenance preparation work, the monitoring of the maintenance process, the analysis and summary of the historical data of the equipment maintenance. The record and statistics of fault type, fault cause and maintenance cost, as well as the statistics of fault records of similar equipment at home and abroad, provide information and service for the maintenance work, follow the analysis of the statistical data, track the changing trend of the reliability of the system and equipment. On the basis of the quantitative management of the beautifying and maintaining equipment of the major means of surrealism, such as the prevention inspection, the maintenance performance, the testing behavior and the monitoring of the running state, the optimization management is guided by the economic analysis of the system benefit, the social analysis and so on.

Maintenance module management and main tasks are shown in Table 1[12]:

Table 1 Main Worksheet of the Overhaul Module

\begin{tabular}{|c|l|}
\hline Professional type & Maintenance of power lines, cable lines, distribution lines and so on \\
\hline Maintenance type & Power equipment maintenance topics are divided into A, B, C, D levels \\
\hline Material quota & Maintenance of spare parts and equipment materials used in the system \\
\hline Process & $\begin{array}{l}\text { Maintain the process part in the maintenance process, quantify and standardize } \\
\text { the site operation. }\end{array}$ \\
\hline Site preparation & $\begin{array}{l}\text { Maintain specific site preparation and maintenance functions. Mainly on-site } \\
\text { preparation, handling related work tickets, work ticket ends. }\end{array}$ \\
\hline Safety measures & $\begin{array}{l}\text { Matters needing attention in all processes such as preparation work, construction } \\
\text { process, acceptance process, and trial operation process, and additions, deletions, } \\
\text { and modifications that need attention in the post-maintenance handover process. }\end{array}$ \\
\hline
\end{tabular}

In this way, the on-site operation information is passed on to the relevant employees in a timely manner, which simplifies the work procedures that need to be performed so that the entire work process is always within the monitoring range, and the accident rate caused by human error is reduced.

\subsubsection{Defect management}

The function module is based on the basic process management of defect detection, defect notification, defect inspection, defect processing, defect information entry, confirmation of defects, and missing information statistics. The information that occurs in the process of deficiencies mainly includes maintenance of basic data of defects, notification of equipment defects, inspection of equipment defects, inquiries of defect notices, entry of deficiencies, confirmation of vacancy information, vacancy registration books, statistics of deficiencies, and eliminations. Missing information query, etc., for technical analysis. Preventing accidental early warning equipment to ensure equipment environmental conditions, defects are an important reference index grading equipment in system stability.

As a guarantee of standardized operations, defect management is an important part of the overall system management. The inspector found that the equipment was defective in his work. Based on his work experience, he judged what type of defect a device or line belonged to, and then recorded the defect information. The operating personnel (maintenance personnel) first fill in the defect list, and the site staff perform preliminary processing. Then the defect list is handed over to the biotechnology department for review, and the biotechnology department reviews and signs it, and a single feedback is 
sent to the department to further repair the system operation. Defective defect processing of equipment. The defect processing flow is shown in Figure 4.

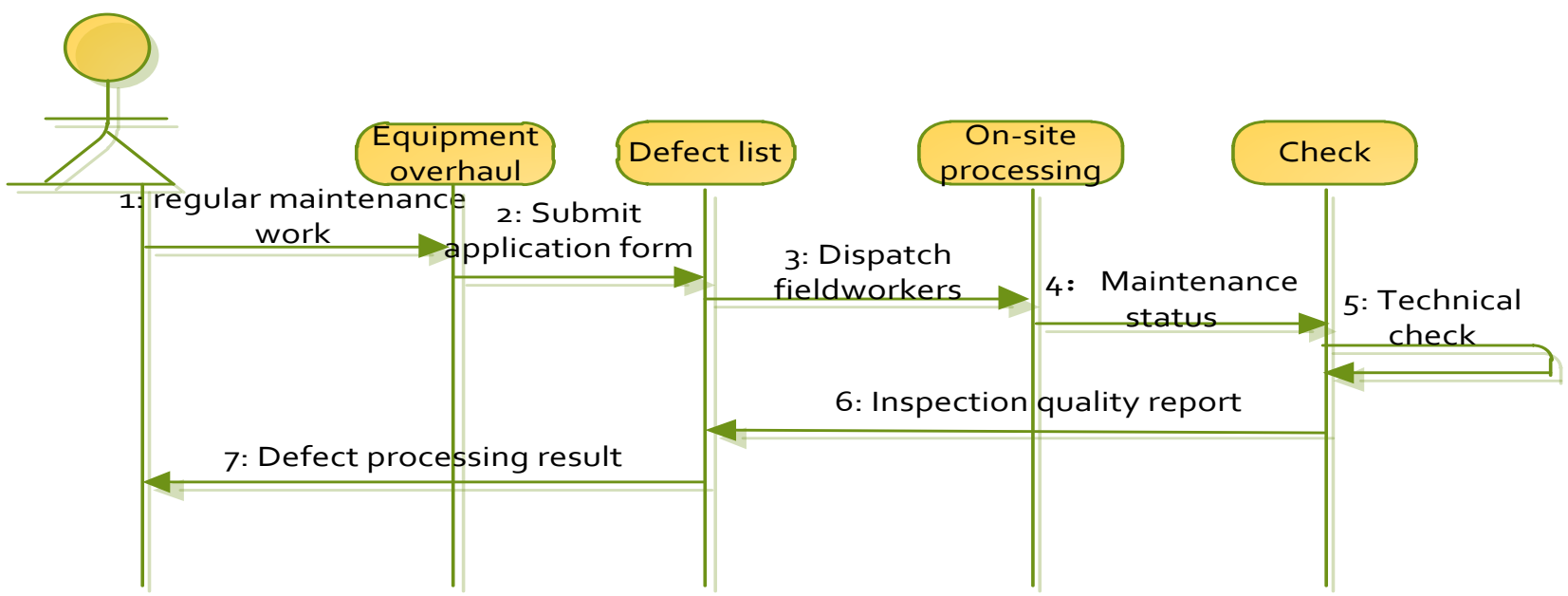

Fig.4 Equipment maintenance timing diagram

\subsubsection{Safety management}

The security management module includes comprehensive equipment safety, personnel safety, system security and tool management security, safety measures in place management, investigation of the causes after the accident, and system status indicators at any time statistical report management, log management and analysis, construction Safety education and training in the case of police training, implementation of safety monitoring and operation and safety supervision and supervision personnel at any time to monitor the main business and related business safety management measures. Safety management is the main content of power field work. This module mainly realizes the following functions:

- The first is the safety inspection of power lines and equipment, and the confirmation of the implementation of the isolation measures must eliminate hidden dangers;

- Allocate enough professional security personnel on site to inspect the equipment. Wherever we work for safe personnel, we shall have at least two full-time security personnel for long-term follow-up of high-risk items, and find that the illegal acts have been corrected;

- The implementation of work cards and safety measures by construction personnel in the maintenance and repair process;

- Check the safe use of tools and maintenance tools, power tools marked clear and lifted within the validity period;

- During the process, maintenance personnel are required to dress strictly and require careful use of various instruments and protective equipment; they can regularly report on unsafe incidents and be responsible for the inspection.

\subsubsection{System Management}

This module provides the login interface of the system. Through the three-level control strategy of users, roles, and permissions, the system's permission control is achieved, and other management modules are activated according to the permissions, providing security for the entire device management system. Its main functions include the creation, management, and adjustment of system 
users and roles, and the assignment of system operation rights; logging and log-in of user login time and various operations of the system, and establishment of corresponding management logs to ensure the system's good operation.

\subsubsection{Basic settings}

This module mainly maintains some basic setup information that the system needs to use.

\subsubsection{Rights management}

The module needs to grant permissions to all users of the system:

- Role maintenance: define and maintain various roles of the system, and formulate different operation modules for each role;

- Menu maintenance: define the system menus that can be operated by users with different rights. The main functions include adding, editing and deleting;

- User Management: Add, modify, and delete system users, manage each user's login account and password, and define roles for each user to control their permissions.

\subsubsection{System maintenance}

This module is mainly responsible for the normal operation and maintenance of the system database and system upgrade and maintenance to ensure the normal and stable operation of the system.

\subsubsection{Log management}

The module records and examines the status of each instantiated work in the system, including:

- Login log: record and view the status of system login personnel;

- Operation log: record all the operations of the user;

- Event log: View abnormal information in user actions;

- Workflow log: record and view the state of each instantiated workflow in the system;

- Device runtime log: View abnormal information during device operation.

\section{Conclusions}

The standardization management of electric power work is a very important work. It is the basic guarantee for the safe operation of the whole power operation. Therefore, it is very necessary to promote the scientific management of the field standardization work in the scope of the whole power system. In the period of operation, the standard operation management system of electric power site can set up the customized instruction book template for different equipment and different work, and then realize the standardized management. In the process of testing, a technician only needs to transfer the instruction template from a job from the template library of the job guidance book, and then work directly on the spot according to a very small amount of parameter modification according to the actual business. No longer only rely on personal experience, greatly reduced the behavior of illegal operations, the standard but strict process design ensures the quality of the field operation, and realizes the simple, easy to use, safe and reliable demand, to prevent all kinds of accidents. In spite of this, there are still some deficiencies in B/S-based standardization management of power job sites, such as relatively poor interactivity and complexity in implementation. In the future, the standardized management of electric power work can seek the organic combination of B/S and C/S, achieve high safety and interactivity, and reduce the complexity of implementation. This has great significance for the future standardization management of electric power work. 


\section{Acknowledgments}

The paper is supported by the Key R\&D Projects of the First Batch of Scientific and Technological Plans in Sichuan in 2017 (2017GZ0068), the Opening Project of Key Laboratory of Higher Education of Sichuan Province for Enterprise Informationalization and Internet of Things (2017WZJ01), Sichuan University of Science and Engineering talent introduction project (2017RCL11), the Education Agency Project of Sichuan Province (18ZB0419) and Education Reform Project of Sichuan University of Science and Engineering (JG-1810).

\section{References}

[1] Song Y, Peng Z P. Design and Implement of B/S Structure-based Power Training Management Information System [J]. Journal of Anhui Electrical Engineering Professional Technique College, 2012.

[2] Ren P. Design and Implementation of Enterprise Internal BBS System Based on B/S Mode [J]. Computer \& Digital Engineering, 2010.

[3] Cheng G X, Xiu-Xian L I. The Design and Implementation of Warehouse Management System in Plastic and Electric Enterprise Based on B/S Structure [J]. Modular Machine Tool \& Automatic Manufacturing Technique, 2008.

[4] Zhang J, Zhu X, Liang X. C/S and B/S Mixed Style and the Application[C]// International Workshop on Education Technology and Computer Science. IEEE, 2009:682-686.

[5] Zhao F, Xu C. Research on the Management Information System of Coal Mine Mechanical and Electrical Equipment Based on B/S Pattern [J]. Modern Mining, 2014.

[6] Wang D. Application of Management Information System of Electric Power Engineering Based on B/S[J]. Electrical Automation, 2012.

[7] Duan J H, Zhang H F, Fang-Jun L I, et al. Research and Design of Desktop Terminal Standardized Management System of Provincial Power Grid [J]. Electric Power Information \& Communication Technology, 2013, 11(10):118-121.

[8] Li J, Chung J Y, Xiao J, et al. On the design and implementation of a home energy management system[C]// International Symposium on Wireless and Pervasive Computing. IEEE, 2011:1-6.

[9] Zhao Q, Han G U. Research on strategy standardization for safety and stability control system of power grid [J]. Guizhou Electric Power Technology, 2014.

[10] Wang Y A, Mu X M, Wang B, et al. Research on Standardized Live working system based on Workflow [J]. Kaoshi Zhoukan, 2014(18):128-129.

[11] Zhao Z. Design and Implementation of Simulation and Training Evaluation System for Sichuan 220 kV Substation [J]. Sichuan Electric Power Technology, 2012.

[12] Jie L I. Design and Implementation of the Electric Power Communication Operation and Management System [J]. Value Engineering, 2014. 